\title{
INTERNATIONAL MANAGEMENT OF CZECH FAMILY \\ ENTERPRISES: DECISIONS ON INTERNATIONAL \\ ENTREPRENEURIAL ACTIVITIES
}

\section{Zapletalová, Š.}

Realization of international entrepreneurial activities is a significant step influencing the business strategy of each enterprise. The paper raises the question of which internal factors, particularly human resources, influence the decisions on the realization of international entrepreneurial activities in Czech family SMEs. The objective of the paper is to determine the effect of selected internal factors on the decisions on the realization of international entrepreneurial activities by Czech family SMEs. The enterprises included in the study are those Czech family SMEs that have already undertaken internationalization activities and were established in the Czech Republic. The research study includes 246 Czech family SMEs. The method included oral questioning and a questionnaire as the principal instruments applied for researching the relationship between human resources and decision making. The results of the research study show the significant influence of human resources on the decision in Czech family SMEs.

Keywords: Czech family SMEs; internationalization process; foreign markets; human resources JEL codes: F23, M16

\section{Introduction and Theoretical Background}

Several studies have analyzed the factors that drive the internationalization activities of SMEs (Gabrielsson \& Kirpalani, 2004; Knight \& Cavusgil, 2004; Filatotchev et al., 2009). The majority of previous studies on internationalization activities have been focused on factors explaining why companies internationalize (Almor \& Hashai, 2004; Autio et al., 2000; Jones \& Coviello, 2005; Knight \& Cavusgil, 2004). The companies that decide to enter international entrepreneurship must be aware both of entrepreneurship opportunities and risks, which are inseparably connected with entrepreneurship. Avoiding business opportunity risks does not lead to economic growth but results in missing business opportunities. The companies that decide to enter international markets undergo particular stages of internationalization. The progress and speed of business activity's internationalization depend on the interest and role that is assumed to the international entrepreneurship within the entrepreneurship strategy of the company.

The factors influencing a company's choice of entry mode are, according to Johanson and Vahlne (1977), divided into two main groups, external factors, and internal factors. Koch (2001) introduced a holistic model of the market entry mode selection process. All factors proposed to influence the market/market entry mode selection process fall into three broad categories: external, internal, and the mixed category. According to Koch (2001), the external category includes industry feasibility, characteristics of the country

An earlier version of this paper has been presented at the International conference on Decision making for Small and Medium-Sized Enterprises (DEMSME 2017) at the School of Business Administration in Karvina, Silesian University. 
business environment, market growth rate, image support requirements, global management efficiency requirements, the popularity of individual market entry modes in the overseas market, market barriers, and so forth. The internal category includes calculation methods applied, management locus of control, market share targets, company size and resources, profit targets, management risk attitudes, experience in using individual market entry modes, and so forth. The third mixed category includes sufficiency and reliability of information inputs, competencies, capabilities, and skills required and available for each market entry modes. Some of the proposed categories of factors may influence each other, adding to the complexity of the decision process.

However, the research on international entrepreneurship and internationalization processes in Czech professional and business literature is relatively scarce; there are only a few studies exploring and monitoring the internationalization processes of Czech SMEs. Due to the absence of substantial research, the author of the present study carried out a research survey among Czech family SMEs to determine the internal factors influencing the decisions of Czech family SMEs on international entrepreneurial activities. We focused on small and medium-sized enterprises from post-transition economies, specifically from the Czech Republic. One of the main reasons of the interest of Czech family SMEs to expand into foreign markets nowadays is the limited market size of the Czech Republic and, consequently, the increasing competition in the domestic market. The growing interest in doing business in foreign markets gives rise to interests in internationalization in a broader context.

The main research question is to find out what factors influence the process of deciding whether or not to enter foreign markets. More specifically, the analysis is aimed at better understanding the factors, especially internal factors, which influence decision-making about entrepreneurial activities in foreign markets. The study is based on primary data collected from a recent survey of Czech family SMEs. The relationships of interest are analyzed using relevant regression techniques and factor analysis. The paper is organized into three parts. The first part outlines selected theories dealing with the internationalization process and factors affecting decision making to enter foreign markets. The second part of the paper aims to present and then interpret results of the survey carried out among Czech family SMEs. Finally, the last section provides the conclusion of the research and offers a discussion of the most important implications. The results of the analysis are discussed, and further recommendations are provided for managers in the last section.

This paper offers several contributions to international business research and attempts to answer calls for studies that span across disciplines. In particular, the paper pays attention to the key role of internal factors in decision-making on international activities. Although we use a single small country, the Czech Republic, as a laboratory to test our theoretical propositions, our study is clearly situated within the domain of international business studies. We offer a new angle on an international business theory by focusing on the process of decision-making on foreign activities. Although the author does not develop a new theory, the work builds on prior works in the field of international business towards a theory of the internationalization of companies. The results of this work contributes new insights on the internationalization process of companies in post-Communist countries. In these countries, there were significant changes in the economic systems 25 years ago, thus a majority of companies have histories shorter than 25 years. 


\section{Data and Methods}

The analysis is based on data from a standardized empirical study, which is comprised of many questions related to the entrepreneurial activities of Czech enterprises in foreign markets. Thus, since the paper is concentrated on various aspects of international activities, only a few questions from the survey we analyzed in this paper. The paper raises the question of which internal factors influence the decisions about entering foreign markets. The objective of the paper is to investigate the effect of human resources on the success of international activities of Czech family SMEs, namely the effect of international experience, and business knowledge of managers.

Therefore, within the above mentioned context, the author proposes the following hypotheses:

Hypothesis 1: The desire for expansion of entrepreneurial activities relates positively to the decision-making process regarding entry into foreign markets.

Hypothesis 2: Efforts to increase sales of the company relate positively to the decision-making process regarding entry into foreign markets.

Hypothesis 3: The level of business knowledge of managers relates positively to the decision-making process regarding entry into foreign markets.

Hypothesis 4: The level of international experience of managers relates positively to the decision-making process regarding entry into foreign markets.

Hypothesis 5: Total available resources of the company relate positively to the decision-making process regarding entry into foreign markets.

Hypothesis 6: Existing contacts of the company to foreign partners relate positively to the decision-making process regarding entry into foreign markets.

Hypothesis 7: Previous import activities of the company relate positively to the decision-making process regarding entry into foreign markets.

The data on the research study we collected in an on-site survey of 246 Czech family SMEs within the period of $09 / 2016-01 / 2017$. We were not able to use official databases as they do not exist for family businesses.

The sample consists of internationally experienced family SMEs in the Czech Republic. Selection of companies researched was based on the method of non-probability purposive sampling, by assumption and occasional selection. The researched companies have already started their internationalization operations, all of them were founded in the Czech Republic, and all of them are private subjects. This delimitation on companies with international experience was made to enable on-site data collection. The focus was on small and medium-sized enterprises, using the European's Union definition based on a headcount of fewer than 250 employees (Eurostat, 2011).

First, telephone calls were made with general managers or CEOs of the Czech companies to explain the purpose of the study and to ask for their participation. A high level of personal involvement consisting of telephone calls and personal delivery and pickup of questionnaires was necessary because of the relatively low response rate in mail surveys in the Czech Republic, and sensitivity to Czech managers' concerns about 
industrial espionage. Moreover, by the first telephone call, some respondents were excluded as they did not meet the established criteria, such as companies with no current international activities, companies distributed to Czech customers' foreign facilities or sister companies within their own corporations. After this step, the samepl consisted of 400 companies from the Czech Republic which met the criteria. In a second step, we hand-distributed questionnaires to the top managers and CEOs. Trained research assistants helped the top managers and CEOs complete the questionnaires, and explained any items that the respondents wished to have clarified. This procedure resulted in 350 questionnaires, out of which 104 we eliminated due to the incompleteness of responses. Thus 246 (a response rate of 70.3\%) questionnaires were used in the subsequent data analysis and statistical processing. The final sample consisted of companies with an average age of 22 years (minimum one; maximum 25), an average size of 54 employees (minimum one; maximum 250). The sample comes from a variety of industries: approximately $52 \%$ in manufacturing, $25 \%$ in retailing, and $23 \%$ in services.

The method of oral questioning and a questionnaire was utilized as the principal instrument for researching the relationship between human resources and the success of international activities. The instrument used in the survey, a structured questionnaire, contains five fields of varying degrees of complexity relating to the area of entrepreneurial activities in international markets. The questionnaire consists of closed, semiclosed and open questions. The questions were designed based on the information gained from experts from business and universities as well as previous research. In some questions, particularly those related to the entry mode choice and market choice, simple and complex scales were used, mostly the Likert-type scale $(5=$ strongly agree to $1=$ strongly disagree). In addition, the questionnaire also included four questions related to the company background (the type of a business sector in the domestic market and international markets; the size of the company measured by the number of employees, and the revenue; the year of company's founding; the year of the first foreign market entry). The questionnaire was pre-tested for instrument validity by 20 managers. In interviews, the managers were asked to respond to the items measuring the theoretical construct. They were also asked to identify any ambiguities revealed in the draft questionnaire. Based on feedback, some minor changes of wording were made.

The decision to enter foreign markets is our dependent variable. The decision to enter foreign markets is monitored in terms of time when the decision was made. Respondents had three variants: decision before the founding of the company, decision during business start-up, or a decision during entrepreneurial activities. Most respondents said that they had decided to enter foreign markets during entrepreneurial activities. Our explanatory variables are these selected internal factors: the desire for expansion of entrepreneurial activities, efforts to increase sales, the level of business knowledge of managers, the level of international experience of managers, total available resources of the company, existing contacts of the company to foreign partners, previous import activities. Questions on the desire for expansion of entrepreneurial activities, efforts to increase sales, existing contacts of the company to foreign partners, and previous import activities were presented in the form of five-point scales ( 5 = strongly agree, $4=$ agree, $3=$ neutral, $2=$ disagree, and 1 = strongly disagree) to ensure maximal respondent specificity. All multi-item measures achieved superior or adequate reliability scores in tests using Cronbach's alpha. The alpha values range from 0.74 to 0.82 . International experience with international 
activities we measured at the company level using prior international work experience (in years), in keeping with prior management research (Beckman and Burton, 2008; Walske and Zacharakis, 2009). International experience includes prior work in a company with international entrepreneurial activities. The average rate of international experience as measured was seven years (minimum 0 years, maximum 45 years). Business knowledge measures knowledge of international markets and knowledge of practices in international markets by company management. The knowledge of international markets plays a key role in the process of the realization of international entrepreneurial activities. Knowledge contributes to increased competitiveness of entrepreneurial subjects in international markets. Questions on the business knowledge of managers were presented in the form of five-point scales ( 5 = strongly agree, $4=$ agree, $3=$ neutral, $2=$ disagree, and 1 = strongly disagree) to ensure maximal respondent specificity. All multi-item measures achieved superior or adequate reliability scores in tests using Cronbach's alpha. The alpha values range from 0.74 to 0.82 . Total available resources of the company are monitored in the categories of tangible resources and intangible resources. Respondents identified their most significant resources. The most important resources were those of intangible character $(81 \%)$. Guided by previous literature and empirical evidence, we have included several control variables. Among the company-level determinants of company performance, the company's size and company age are the two most widely used demographic characteristics of companies. Therefore, we include company size (natural logarithm of the number of employees) and company age (in years). In addition to the company-level determinants, we also include the industry level of the company: whether the company operates in the manufacturing or service sector. We included a dummy variable for industry level, as Acquaah and Yasai-Ardekani (2007) did because the distinction between manufacturing and services obviously has a considerable effect on company performance.

Table 1 | Descriptive statistics and Pearson correlation

\begin{tabular}{|c|c|c|c|c|c|c|c|c|c|c|c|c|c|}
\hline & mean & SD & 1 & 2 & 3 & 4 & 5 & 6 & 7 & 8 & 9 & 10 & 11 \\
\hline Decision & 2.10 & 0.96 & 1 & & & & & & & & & & \\
\hline Size & 53.98 & 60.53 & 0.06 & 1 & & & & & & & & & \\
\hline Age & 31.53 & 37.86 & $0.12^{*}$ & $0.39 * *$ & 1 & & & & & & & & \\
\hline Industry & 2.26 & 1.64 & $0.14^{* *}$ & $-0.12^{*}$ & $-0.11^{*}$ & 1 & & & & & & & \\
\hline Expansion & 0.53 & 0.50 & $0.16^{* *}$ & $0.17 * *$ & 0.10 & -0.01 & 1 & & & & & & \\
\hline Sales & 0.82 & 0.39 & -0.06 & -0.05 & $-0.18^{* *}$ & -0.05 & $0.18^{* *}$ & 1 & & & & & \\
\hline Knowledge & 3.88 & 0.86 & $-0.17 * *$ & $0.31^{* *}$ & $0.19^{* *}$ & -0.06 & 0.10 & $-0.17^{* *}$ & 1 & & & & \\
\hline Experience & 6.40 & 8.54 & $0.16^{* *}$ & 0.09 & 0.07 & -0.02 & 0.02 & 0.024 & $0.16^{* *}$ & 1 & & & \\
\hline Resources & 0.20 & 0.40 & $-0.17 * *$ & 0.10 & $0.16^{* *}$ & -0.10 & -0.03 & 0.02 & $0.20^{* *}$ & -0.08 & 1 & & \\
\hline Contact & 0.53 & 0.50 & -0.08 & $-0.16^{* *}$ & $-0.12^{*}$ & 0.05 & -0.09 & 0.06 & -0.06 & 0.06 & -0.01 & 1 & \\
\hline Import & 0.05 & 0.21 & -0.02 & -0.08 & 0.03 & $0.17^{* *}$ & -0.07 & -0.04 & 0.01 & -0.03 & 0.09 & 0.04 & 1 \\
\hline
\end{tabular}

Significance level: ${ }^{*} p<0.05 ;{ }^{* *} p<0.01$

Source: own research 
To test the theoretically derived model, we processed the data in SPSS. The descriptive statistics are described in Table 1. Table 1 illustrates the intercorrelations among the variables that were obtained from the Pearson correlation matrix. The values indicating intercorrelations among the predictor's variables were low, ranging from 0.01 to $0.39(\mathrm{p}<0.01)$, thus indicating the independence of the variables used for measuring the predictors. As the descriptive data revealed a promising variation as well as correlation among the variables included in the model, we have reason to believe that it would find support for the hypotheses.

We used hierarchical moderated regression analysis (ordinary least-square OLS regression techniques) to test the hypotheses. Before testing them, we controlled for multicollinearity in the dataset. For this purpose, we calculated the VIF values for the independent variables. In our analysis, the VIF values were all below 1.1, which is a relatively low and acceptable level. Consequently, there is no reason to believe that there is any major multicollinearity in the regression that could lead to misinterpreting or overestimating the final model and its predictive ability. Table 2 presents the results.

Furthermore, factor analysis has been carried out due to the specification of internal factors affecting the decision-making to enter foreign markets. The criteria (internal factors) are based on information offered due to personal communication with selected experts from businesses and universities and on the basis of previous research. Respondents expressed their opinion on the importance of each criterion with the help of the five-point Likert Scale ( $5=$ strongly agree to $1=$ strongly degree). The reliability of measurements was acceptable. The total reliability reached the value of $\alpha=0.799$, standardized item $\alpha=0.803$. Then Varimax rotation was performed: 4 factors with eigenvalues greater than one were extracted. The factors loading greater than 0.5 are shown in bold. The results of the factor analysis are shown in Table 3.

\section{Results}

The first model (Model 1 in Table 2) is a baseline model that shows the effects of control variables on the decision-making to enter foreign markets. In the second model (Model 2 in Table 2), the main terms of the independent variables are entered into the regression.

Overall, the control variables explain little of the variance. Model 1 and Model 2 indicate that age and industry have a positive and significant effect on the decision-making to enter foreign markets, while size has an insignificant effect on the decision of Czech family SMEs.

The desire for expansion of entrepreneurial activities in Model 2 has a positive and insignificant effect on decision-making to enter foreign markets. Hypothesis 1 is supported. The efforts to increase sales of the company has a negative and insignificant effect on decision-making to enter foreign markets. Hypothesis 2 is not supported. The level of business knowledge of managers has a positive and significance effect on decision-making process regarding entry into foreign markets, in line with hypothesis 3. The variable level of international experience of managers is positive and significant; hypothesis 4 is supported. The variable total available resources of the company in Model 2 is positive and significant; hypothesis 5 is supported. As indicated in Model 2, existing contacts of the company to foreign partners and previous import activities of the company have a negative and insignificant effect on the decision-making of entering foreign markets; hypothesis 6 and hypothesis 7 are not supported. 
Table 2 | Determinants of Decision-Making

\begin{tabular}{|l|c|c|}
\hline & \multicolumn{2}{|c|}{ Dependent Variables } \\
& Model 1 & Model 2 \\
\hline Size & 0.026 & 0.061 \\
\hline Age & $0.129^{*}$ & $0.151^{* *}$ \\
\hline Industry & $0.158^{* *}$ & $0.139^{* *}$ \\
\hline Expansion (H1) & & $0.159^{* *}$ \\
\hline Sales (H2) & & -0.070 \\
\hline Knowledge (H3) & & $0.178^{* *}$ \\
\hline Experience (H4) & & $0.161^{* *}$ \\
\hline Resources (H5) & & $0.155^{* *}$ \\
\hline Contacts (H6) & & -0.039 \\
\hline Import (H7) & & -0.026 \\
\hline $\mathbf{R}^{2}$ & & 0.26 \\
\hline$\Delta \mathbf{R}^{2}$ & 0.14 & 0.22 \\
\hline Adj. R & & 0.23 \\
\hline F & 0.14 & $6.387^{* *}$ \\
\hline
\end{tabular}

Significance level: ${ }^{*}-p<0.05{ }^{* *}-p<0.01$

Source: own research

The factor analysis extracted four factors with an eigenvalue greater than 1: along with the observed loadings, this indicates the convergent and discriminant validity of these constructs. The factor loadings structure was employed to determine the factor scores of each company on the four constructs. All the scale items loaded highly on factors they represented and weakly on other factors. The four factors accounted for $87.7 \%$ of the total variation in the sample.

Those four factors determine the internal factors affecting the decision-making of Czech family SMEs to enter foreign markets. Factor 1 "human factor" is formed by the factors of managers' abilities (level of business knowledge and level of international experience). Factor 2 "growth factor" characterizes the growth reasons for entering foreign markets (desire for expansion and efforts to increase sales). Factor 3 "resource factor" is associated with the resources (tangible and intangible resources) available for entry into foreign markets. Finally, factor 4 "contact factor" defines characteristics of the company associated with the existing contacts of the family SMEs to foreign partners. 
Table 3 | Determinants of Decision-Making

\begin{tabular}{|l|c|c|c|c|}
\hline \multirow{2}{*}{} & \multicolumn{4}{|c|}{ Factors } \\
\cline { 2 - 5 } & $\mathbf{1}$ & $\mathbf{2}$ & $\mathbf{3}$ & $\mathbf{4}$ \\
\hline Expansion & 0.211 & $\mathbf{0 . 7 2 0}$ & -0.083 & -0.286 \\
\hline Sales & -0.237 & $\mathbf{0 . 7 9 3}$ & 0.034 & 0.267 \\
\hline Knowledge & $\mathbf{0 . 7 9 3}$ & -0.053 & 0.264 & -0.204 \\
\hline Experience & $\mathbf{0 . 6 7 4}$ & 0.053 & -0.319 & 0.423 \\
\hline Resources & 0.181 & 0.104 & $\mathbf{0 . 8 0 4}$ & -0.099 \\
\hline Contacts & -0.012 & -0.0055 & 0.095 & $\mathbf{0 . 8 1 8}$ \\
\hline Import & -0.110 & -0.157 & 0.471 & 0.238 \\
\hline
\end{tabular}

Extraction Method: Principal Component Analysis. Rotation Method: Varimax with Kaiser Normalization Source: own research

\section{Conclusion}

Changing conditions and market structures demand that many small and medium-sized enterprises devise new strategies as they search for a competitive place in their home markets and take advantage of emergent market opportunities. The participation of entrepreneurial subjects in international business is one possibility of strengthening competitiveness. The Czech Republic is a country with a high share of exported and imported goods in its GDP, which is typical of small countries such as the Czech Republic. The Czech entrepreneurial subjects have been increasingly taking part in foreign markets since the beginning of the $21 \mathrm{st}$ century, and this trend seems to be growing. Most companies are aware of the necessity to develop their business and entrepreneurial activities on an international scale. The necessity of active participation of Czech family SMEs in a foreign market is conditioned primarily by the character of Czech economics and its foreign political orientation.

The objective of this paper was to determine the internal factors influencing the decisions of Czech family SMEs on the realization of international entrepreneurial activities. The reason for this choice is that the issue of internationalization activities is becoming increasingly important for small and medium-sized companies, especially those that are technologically driven and which internationalize during the early stages of their organizational lives (Almor 2006). The results show that the desire for expansion (H1), the level of business knowledge of managers (H3), the level of international experience of managers (H4), and total available resources of the company (H5) are significantly associated with the decision making of Czech family small and medium-sized enterprises to enter foreign markets. When Czech family SMEs decide to enter foreign markets, they are affected by various factors. With the help of factor analysis, four factors have been identified. These factors can be classified into four main groups: human factors, growth factors, resource factors, and contact factors. The degree of influence of each group of factors was determined based on the average of the mean values. The level of business knowledge of managers has the greatest influence on decision making. 
This study has some contributions, including theoretical contributions and managerial implications. This study has provided some theoretical contributions as follows: It gives additional insight into the influence of internal factors on the decision making on international entrepreneurial activities. Furthermore, we also provide some implications for managers and owners of Czech enterprises. This study helps managers to understand how the internal factors affect the decision making on international activities of family SMEs.

\section{Figure 1 | Effect of Selected Internal Factors on Decision-Making to Enter Foreign Markets}

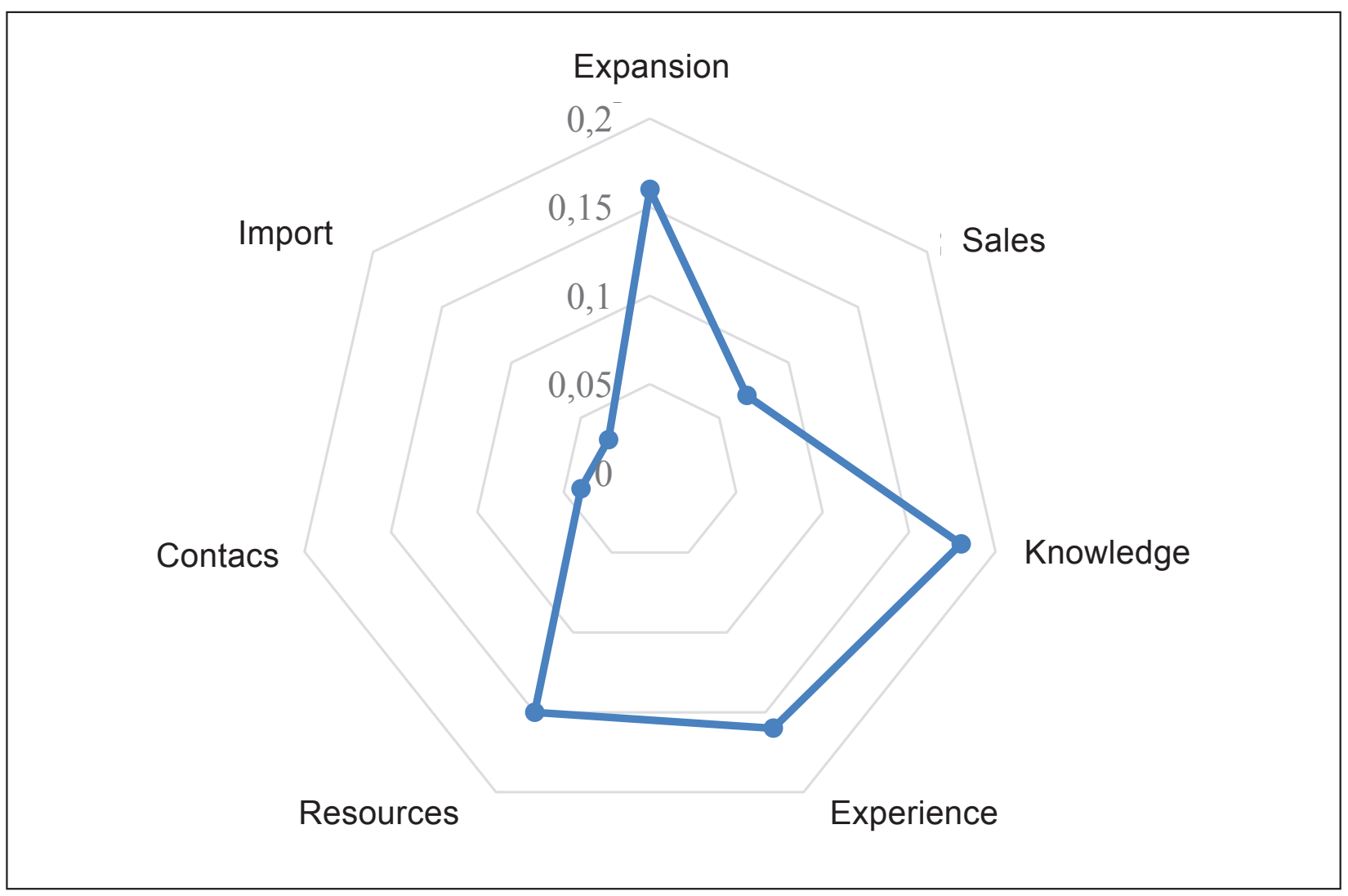

This study also has some limitations. First, this study has been conducted only in one small country, in the Czech Republic. Indeed, this will affect the generalizability issue. This study only examined the relationship between selected internal factors and decision making on international activities. Hence, the researcher cannot justify it as a generalization for all European countries. Due to time and cost limitations, this study employed a cross-sectional study. Thus, it only portrays the phenomena at a single point in time, and it will not be able to reflect the long-term effects of the change.

This study suggests several recommendations for future research. The study might be extended to multiple countries in Europe. The future research might use a longitudinal study which describes phenomena over the long-term. The longitudinal study may lead practitioners and academics to understand the causal relationship between factors (internal and external) and decision making on international activities. 


\section{References}

Aaby, N. E., \& Slater, S. F. (1989). Management Influences on Export Performance: A Review of the Empirical Literature 1978-88. International Marketing Review, 6(4), 7-26.

Acquaah, M., \& Yasani-Ardekani, M. (2007). Does the Implementation of a Combination Competitive Strategy Yield Incremental Performance Benefits? A New Perspective from a Transition Economy in Sub-Saharan Africa. Journal of Business Research, 61, 346-354.

Almor, T. (2006). Conceptualizing path of growth for the born global firms', paper presented at the Annual Conference on Corporate Strategy (ACCS), Berlin

Almor, T., \& Hashai, N. (2004). Competitive Advantage and Strategic Configuration of Knowledge-Intensive, Small and Medium-Sized Multinationals: A Modified ResourceBased View. Journal of International Management, 10(4), 479-500.

Autio, E., Sapienza, H. J., \& Almeida, J. G. (2000). Effects of Age a Entry, Knowledge Intensity and Imitability on International Growth. Academy of Management Journal, 43(5), 909-924.

Beckman, C. M., Burton, M. D., \& O'Reilly, C. (2007). Early Teams: The Impact of Team Demography on VC Financing and Going Public. Journal of Business Venturing, 22(2), 147-273.

Eurostat (2011). Summary Indicators - Employment Size Classes for EU25/EU27 (all NACE activities). Retrieved September 2, 2017 from http://appsso.eurostat.ec.europa.eu/nui/ setupModifyTableLayout.do.

Filatotchev, I., Liu, X., Buck, T., \& Wright, M. (2009). The Export Orientation and Export Performance of High-Technology SMEs in Emerging Markets: The Effects of Knowledge Transfer by Returnee Entrepreneurs. Journal of International Business Studies, 40(6), 1005-1021.

Gabrielsson, M., \& Kirpalani, V. H. (2004). Born Globals: How to Reach New Business Space Rapidly. International Business Review, 13(5), 555-571.

Johanson, J., \& VahIne, J. E. (1977). The internationalization process of the firm-A model of knowledge development and increasing foreign market commitments. Journal of International Business Studies, 8, 23-32.

Jones, M. V., \& Coviello, N. E. (2005). Internationalization: Conceptualising an Entrepreneurial Process of Behaviour in Time. Journal of International Business Studies, 36(3), 284-303.

Keupp, M. M., \& Gassmann, O. (2009). The Past and the Future of International Entrepreneurship: A Review and Suggestions for Developing the Field. Journal of Management, 35(3), 600-633.

Knight, G. A., \& Cavusgil, S. T. (2004). Innovation, Organizational Capabilities, and the BornGlobal Firm. Journal of International Business Studies, 35(2), 124-141.

Koch, A. J. (2001). Factors influencing market and entry mode selection: Developing the MEMS model. Marketing Intelligence \& Planning, 19(5), 411-432.

Onkelix, J., Manolova, T. S., \& Edelman, L. F. (2016). Human Capital and SME Internationalization: Empirical Evidence from Belgium. International Small Business Journal, 34(6), 818-837.

Uhlenbruck, K., \& Decastro, J. O. (2000). Foreign Acquisitions in Central and Eastern Europe: Outcomes of Privatization in Transitional Economies. Academy of Management Journal, 43(3), 381-402.

Wales, W. J., Gupta, V. K., \& Mousa, F. T. (2013). Empirical Research on Entrepreneurial Orientation: As Assessment and Suggestions for Future Research. International Small Business Journal, 31(4), 357-383. 
Walske, J. M., \& Zacharakis, A. (2009). Genetically Engineered: Why Some Venture Capital Firms are more Successful than Others. Entrepreneurship: Theory and Practice, 33(1), 297-318.

Weinzimmer, L. G., Nystrom, P. C., \& Freeman, S. J. (1998). Measuring Organizational Growth: Issues, Consequences and Guidelines. Journal of Management, 24(2), 235-262.

\section{Author}

Ing. Šárka Zapletalová, Ph.D.

Assistant Professor

Department of Business Economics and Management

School of Business Administration in Karviná

Silesian University in Opava

zapletalova@opf.slu.cz

This paper is the outcome of the Student Competition Grant, project no. SGS 24/2016 (Silesian University in Opava) Lidské zdroje v rodinných podnicích - Human Resources in Family Businesses. 